the second of whom, together with the placenta, was cedematous. The liver showed small-celled infiltration "exactly similar to that seen in congenital syphilitic cirrhosis." The placenta was very large and the villi were filled with cells and the vessels obliterated.

Seifart' has described the case of a woman who, after three normal confinements, had premature labour induced owing to acute nephritis, and both the foetus and placenta were dropsical.

Munster ${ }^{6}$ has reported the case of a woman who developed cedema before the birth of an oedematous child. No account of the morbid anatomy is given.

MacWatters $^{\top}$ has also reported a case of foetal anasarca occurring in a primipara aged 30 years. The patient had albuminuria and casts in the urine; there was no history of syphilis. Labour was difficult owing to the large size of the ehild and the friability of the tissues. The heart, the kidneys, the bladder, and the liver were normal. The placenta was "soft, friable, and similar to a diffluent spleen." Dr. MacWatters informs me that the patient has since been delivered of three healthy children.

The main conclusions to be drawn appear to be that cdematous children are usually born of women of about the ages of from 30 to 35 years who have had previous abortions or premature stillbirths. 'The mother's health is rarely good but there is no specific disease associated with this condition. Evidences of syphilis, though generally looked for, have only been found in a few cases. Fœetal anasarca may occur in single or twin pregnancies, and may be associated with hydramnios. The labour is usually premature but the large size of the child often causes obstruction during labour and the friability of the tissues when present renders artificial aid difficult. While the maternal prognosis is good the children are either stillborn or only live a few hours. Lastly, subsequent preguancies may end either normally or with premature stillbirths or, in a few cases, with more oedematous children.

The causation of this condition is very obscure but the facts at our disposal seem to point to an inmediate fotal and a more remote maternal origin. The almost invariable illhealth of the mother, together with her bad obstetric history, makes it impossible to leave the maternal factor out of account, but seeing that, in many cases at all events, a definite fcetal abnormality has been found which is sufficient to account for the condition it seems more profitable to look primarily for a foetal causation of the dropsy.

The reported cases may be considered under two headings, first. those in which a definite mechanical circulatory obstruction exists; and secondly, those in which no such condition is present. In the former class would be such cases as a closed foramen ovale," stenosis of the great vessels, ${ }^{3}$ absent lymphatic system, ${ }^{10}$ or cirrhosis of the liver, ${ }^{11}$ and these abnormalities may in themselves be sufficient to account for the anasarca; but in the last-named class we have no such gross changes to guide us, and as a rule no explanation at all has been put forward. Hence in my first case, since no circulatory obstruction existed, a systematic examination of all the organs was made and the only ones showing definite pathological changes were the suprarenals. The disorganisation of these organs, as compared with those of a normal six months foetus, was very evident. It is of course necessary to exclude post-mortem changes, as the fœetus must have been dead for at least a week before delivery, but the tissue does not present the appearances of disorganisation which might be expected, and the cells take up the stain so definitely that these changes cannot be considered as post-mortem results. The small-celled infiltration of the cedematous interstitial tissue, which was so obvious in the suprarenals, was not present in the other organs or tissues except to a slight extent in the liver. In the adult the suprarenal cortex has been credited with the function of neutralising certain toxic products of metabolism, and in riew of the large size of the cortex of the fotal suprarenal it is probable that it has some similar function to perform.

5 .tmerican Journal of Obstetrics, 1899, vol. cxxxix., p. 127. 6 THF LA YCF', Jan. 25th, 1902, p. 224.

× Lawson Tait: Transactions of the Obstetrical Society of London, 1876, vol. xvii., p. 307.

"Pott: Jahrbuch fur Kinderheilkunde, Pand xiii., p. 11.

1" Smith and Birmingham: Joumal of Anatomy and Physiology vol. xxiii, p. 532 .

ii Gazetta Medica di Torin, No. 2, p. 21
These changes in the suprarenals have suggested that some direct relationship may exist between them and the production of the cedema. Were it found in the majority of similar cases that these organs presented pathological changes it might be possible to attribute the cedema to the action of certain unneutralised products of metabolism upon the fotal capillary endothelium. In such cases the oedema of the fotus would be considered to be of toxic origin.

I am indebted to Professor Walter C. Swayne, obstetric physician to the Bristol Royal Infirmary, for his permission to publish these cases. I also wish tc express my thanks to Professor I. Walker Hall, pathologist to the Bristol Royal Infirmary, for his opinion on some of the sections and for other valuable aid.

Bath.

\section{A CASE OF DOUBLE ABDOMINAL HYDROCELE.}

BY OWEN RICHARDS, M.A., M.D., M.CH. OXON., F.R.C.S. ENG.,

SLRGFON TO KASR-EL-AINY HOSPITAL, CAIRO, AND PROFFSSOR OF CLINICAL SURGERT IN THE EGYPTIAN GOVERMMEX' MEDICAL SCHOOL.

I HAVE thought it worth while to report this case because it is a very well-marked example of a condition which has led at times to difficulties in diagnosis. It is referred to with two figures in von Bergmann's recent "System," but otherwise it receives hardly any notice in those text-books which I have been able to consult, and its treatment none.

A Soudanese, aged about 45 years, was admitted to the Kasr-el-Ainy Hospital for abdominal tumour. He said that he noticed nothing till a month ago; he had since had itching of the scrotum, vague pains and numbness in the left leg, frequent micturition (perhaps due to pressure on the bladrler), and gradual swelling of the scrotum and abdomen. The swelling began in the bottom of the scrotum on the left side and extended upwards; it was shortly followed by a similar swelling on the right side. There had been no pain and no history of strain, injury, or syphilis. This history was, of course, unreliable, especially as regards dates.

On examination there was a large hydrocele on the left side, extending upwards into the internal abdominal ring. At its lower end was a projecting pouch and where this joined the main mass a hard tender lump could be felt, apparently the testis. On the right side was another hrdrocele, consisting of three portions. Of these one filled the scrotum and the second extended superficially two inches above Poupart's ligament. The third filled the iliac fossa and extended deeply across the middle line, reaching just above the umbilicus. Fluctuation was free between all three and on contracting the recti the third could no longer be felt, while the other two became tense. The scrotal sac had several hard plates in its walls.

At the operation the left sac, which held 32 ounces, was found to reach just within the internal abdominal ring. The testis and cord were dissected from it, the sac removed, and the canal closed by Bassini's method. On the right side the sac held 55 ounces of fluid, which, like that in the other, was turbid with cholesterin. The superficial part lay beneath the tendon of the external oblique, which was stretched and thin. This and the scrotal portion were separated and the cord and testis preserved. It was then found that the whole of the deep sac could gradually be pulled down and strippech from the peritoneum (which was not opened) through the internal ring. When this had been done the whole hand could be passed through the ring into the abdomen, up to the division of the aorta, pushing the peritoneum in front of it. The space left by the sac lay between the peritoneum and the abdominal wall. The peritoneum came down fairly well to obliterate it, but a certain amount of dead space was left which was drained by a separate incision. The ring was then narrowed as on the other side and the tendon of the external oblique reefed over it. The drainage-tube was removed after two days. The only interruption to healing was a small subcutaneous abscess which formed after some time round one of the sutures in the external oblique and closed rapidly on its removal. In the sac removed from the right side, in addition to the pouches mentioned above, there was found one shaped like a flask, with a circular calcified 
tubular opening admitting the finger, running for about two and a half inches upwards and outwards from the internal ring, deep to the parietes, and separate from the main abdominal sac ( 0 in illustration).

Several views have been advanced as to the way in which these sacs arise; they will be found mentioned in Mr. J. Lacy Firth's paper. According to the simplest of these, which is endorsed by Jacobson, Réclus, and others, the abdominal sac is merely a lateral bulging of the upper part of the processus vaginalis. For, given a processus which is paten from testis to internal ring, any increase of pressure (as in the case of a varicose vein) will not only widen it but lengthen it, so that it projects in both directions, downwards

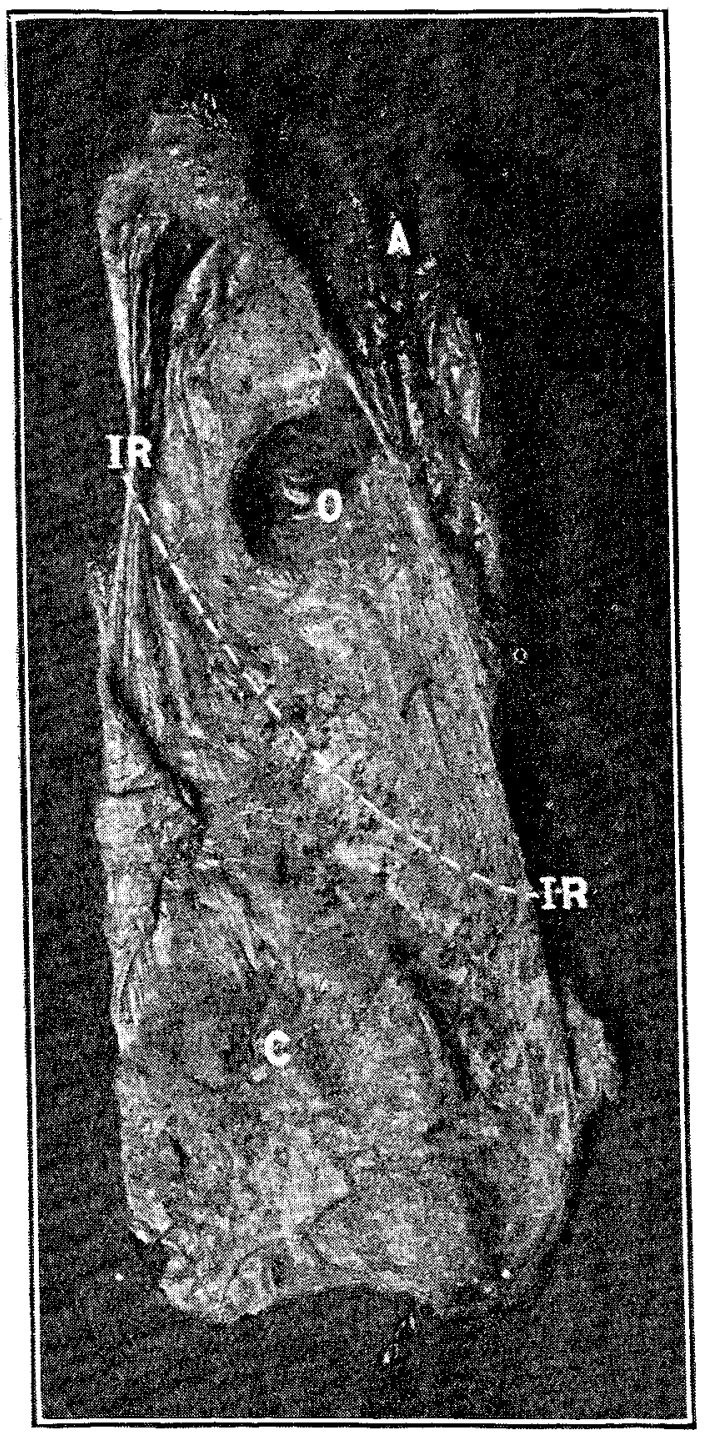

A marks abdominal portion of sac much shrunk. o, Opening of pouch. I R, Level of the internal ring. C, Calcareous plates in scrotal portion of sac.

between the legs and upwards into the abdomen. This stage is illustrated by the left side of this case, where the upper end of the sac formed a blunt projection into the abdomen. With continued increase there will be produced lateral bulgings wherever the wall is weaker than elsewhere or the outside pressure less. Such secondary pouches are common in large scrotal hydroceles; one existed in the left side of the scrotum in this case. Two such pouches seem to have been formed high up on the right side, one beneath the external oblique, the other within the abdomen. The small pouch with the calcified annular opening which lay just inside the ring might perhaps be considered as the original upper end of the processus, prevented from sharing in a general dilation by an early calcification of its walls. Anyhow, the fact that the sac lay in front of the peritoneal bag is against its having originated in the tract of the gubernaculum, which lies behind. Mr. Lacy Firth refers to 25 cases of this condition, 18 foreign collected by Villeneuve and seven British. Lieutenant-Colonel J. Lewtas has since published one, and Captain Herbert describes one which he says is the third which has occurred at his hospital. My colleague, Mr. F. C. Madden, tells me that he has met with two cases in this hospital. Probably the condition is not really very rare, especially in those countries in which large hydroceles are common. I have only been able to consult a very few of the recorded cases, but in more than one of them the diagnosis has only been made at operation, and it is possible that a good many others escape recognition or are simply tapped.

As regards treatment, injection is dangerous and tapping merely palliative. The choice lies between drainage and extirpation of the sac. Drainage may succeed in a case where the sac is small and can be packed to the top, more especially if, as in the older cases, it suppurates. But a big sac cannot be filled with packing, and on the analogy of scrotal hydrocele one would confidently expect it to refill so long as two uninjured serous surfaces are left opposite one another. In Colonel Lewtas's case, treated by drainage for nine days, there was apparently no reaccumulation when the patient was discharged after three weeks. But in this case a collection of two and a half pints was only recognised in the course of operation, and it is unlikely that the accumulation of 12 days would be any more evident. At any rate, even if drainage is likely to prevent recurrence, extirpation is certain to.

As regards the difficulty of getting away the whole sac I was prepared in my own case to meet with a good deal and expected to have to divide the abdominal muscles. As a matter of fact, it was perfectly easy. The same seems to have been the experience of Mr. Lacy Firth, who removed a large sac easily and entirely through a much smaller ringone which only admitted two fingers. So clearly the size of the sac and the narrowness of the ring need not mean diffculty, and it seems worth while for the surgeon in such cases to try whether the sac cannot be stripped out in this way before dividing the abdominal wall or resigning himself to drainage.

References.-Lacy Firth : Brit. Med. Jour., Nov. 16th, 1901 (case and references). Lewtas: THE LANCEr, Feb. 25th, 1905, p. 489 (case). Herbert: Brit. Med. Jour., April 22nd, 1893 (case). Holmes and Hulke's System of Surgery, vol. iii., p. 492 (two cases).

Cairo.

\section{A CASE OF CONGENITAL HYPERTROPHIC STENOSIS OF THE PYLORUS TREATED MEDICALLY}

By NORTON B. CLOWES, M.R.C.S. ENG., L.R.C.P. LOND.

THE baby (a boy) was born on Nov. 24th, 1907, the birth being quite natural. The parents were quite healthy; the mother had had three previous confinements, two girls and one boy, all of whom were very healthy children, and as the mother was unable to nurse them they were all brought up from the first on Allenburys food and all thrived well on it. This baby weighed 11 pounds at his birth and was in every way one of the healthiest infants it was possible to behold. As was the case in the other children feeding was commenced on the second day with Allenburys No. 1 food and for the first fortnight, although he did not increase in weight, he appeared fairly comfortable, a little restlessness and flatulence being the only troubles. From this time to the eighteenth day (Dec. 12th) he began being very uncomfortable after his feeds, had a good deal of pain, and was slightly sick once or twice in the 24 hours. This sickness rapidly became worse, taking the form of vomiting of whole feeds almost immediately after they had been swallowed, once or twice in the day or perhaps missing a day and then bringing up feeds three or four times in the 24 hours. Even with this he did not appear to have lost much flesh, but on weighing it was found he had lost 5 ounces on Dec. 15th (his twenty-first day). As the vomiting had become very troublesome he was put on a mixture of milk sugar, 2 ounces dissolved in 25 ounces of boiling water (strained), with 2 ounces of milk and 3 ounces of cream, and $1 \frac{1}{2}$ ounces of lime water added. One and a half ounces of this were tried every two hours and for a day or two the baby seemed better. The sickness returned, other foods were tried, and on Dec. 20th his weight was 10 pounds 6 ounces. He had become very constipated; he only had very small motions of soft, brown, gelatinouslooking material, with a few very small curds in them. On the 26 th his weight was 10 pounds and he was put on 